\title{
Tel Erozyon Tezgahlari ile Üretilen Makine ve Kalıp Elemanlarının Üretim Maliyetleri Açısıdan İncelenmesi
}

\author{
${ }^{* 1}$ Gültekin Basmac1, ${ }^{2}$ Mustafa Ay, ${ }^{3}$ Ayhan Etyemez, ${ }^{4}$ Coşkun Paksoy \\ ${ }^{1}$ Mühendislik-Mimarlık Fakültesi, Makine Mühendisliği Bölümü Burdur Mehmet Akif Ersoy Üniversitesi, \\ Burdur, Türkiye \\ ${ }^{2}$ Teknoloji Fakültesi, Makine Mühendisliği Bölümü Marmara Üniversitesi, İstanbul, Türkiye \\ ${ }^{3}$ Nikken, Istanbul, Türkiye \\ ${ }^{4}$ Uluslararası Mülteci Eğitim Merkezi, Ankara, Türkiye
}

\section{Özet}

Çağımız üretim ve imalat sanayi için, imalat ve üretim hızlarının artırılması, üretimi etkileyen en önemli faktörlerden biri haline gelmiştir. Ürün ya da hizmetin mümkün olan en hızlı şekilde son kullanıcıya ulaştırılması üretim, stok ve pazarlama maliyetlerini önemli ölçüde etkilemektedir. Bu sebeple makine imalat sektörlerinin tamamında, uzay-havacılık, otomotiv, tüm kalıp imalat sektörlerinde yüksek hassasiyet ve yüzey pürüzlülük değerlerine sahip imalat teknikleri önem kazanmaktadır. Bu amaçla özellikle tel erozyon ile imal edilen makine parçaları ve kalıp elamanları ön plana çıkmaktadır. Bunun sebebi yüksek konum, tolerans, yüzey pürüzlülüğü değerleridir. Uygun parametreler ve tel ile birkaç farklı operasyonla elde edilebilecek tolerans değerleri daha hızlı ve kolay elde edilebilir. Bilinen talaşlı imalat yöntemleri ile üretilen makine elemanlarının yüzey pürüzlülüğü değerlerini iyileştirmek için ise üretim maliyetlerini artıran bir dizi taşlama ve parlatma işlemleri yapılmaktadır. Tel erozyon ile üretilen makine parçaları ve kalp elemanları ise bu işlem safhalarının bir ya da birkaçını atlayarak daha ölçü tamlığ 1 ve tolerans hassasiyetine sahip yüzey pürüzlülük değerleri neredeyse taşlama ile elde edilen yüzey pürüzlülük değerlerine sahip ürünler elde edilmektedir. Burada talaşlı imalat ve tel erozyonda imal temrinlerin ölçü tolerans değerleri, yüzey kalitesi, pürüzlülük değerlerini deneysel olarak inceleyip, sonuçlarını kıyaslayarak makine ve imalat sanayinde üretim maliyetlerinin düşürülmesine yönelik çalışma yapılacaktır.

Anahtar Kelimeler: Tel erozyon, yüzey kalitesi, konum toleransı, kalıpçılık, ölçü toleransı

\section{Investigation of Machine and Mold Elements Produced by Wire Erosion Machines in Terms of Production Costs}

\begin{abstract}
Production and manufacturing industry products, increasing production and production speeds ensuring production and making it one of the most important factors. The fastest possible delivery of the product or service to the end user has a significant impact on production, inventory and marketing costs. For his reason, manufacturing techniques with high precision and surface roughness values gain importance in all machinery manufacturing sectors, aerospace, automotive and all mold manufacturing sectors. For this purpose, machine parts and mold elements produced by wire erosion come to the forefront. This is
\end{abstract}

*Sorumlu Yazar: Adres: Mühendislik-Mimarlık Fakültesi, Makine Mühendisliği Bölümü Burdur Mehmet Akif Ersoy Üniversitesi, TÜRIYE. E-mail: gbasmaci@ mehmetakif.edu.tr, Gsm: +902482132715 
due to the high position, tolerance, surface roughness values. With the appropriate parameters and wire, tolerance values that can be obtained by several different operations can be obtained more quickly and easily. In order to improve the surface roughness values of the machine elements produced by known machining methods, a series of grinding and polishing processes are carried out which increase the production costs. Machine parts and mold elements produced by wire erosion, while skipping by wire erosion, while skipping one or more of these process stages, surface roughness values with higher dimension and tolerance sensitivity are obtained products with surface roughness values obtained by almost grinding. The aim of this study is to make a scientific study to reduce the production costs in the machine and manufacturing industry by experiencing experimentally the surface tolarence and roughness values of the measurement tolerances of the machining and wire erosion terminals.

Key words: Wire EDM, surface quality, position tolerance, mold, dimension tolerance

\section{Giriş}

İleri ve alaşımlı mühendislik çeliklerinin ve metallerin ortaya çıkışı ile geleneksel imalat yöntemleri yani talaşlı üretim metotları oluşan ihtiyaca cevap veremedi, karmaşık şekilli modellemeler ve bunlarla birlikte biraz daha büyüyen ileme zorlukları sanayi devriminden bu yana malzeme alanında her yeni buluş ve keşifle birlikte daha da zorlaşmıştır.

Yapılan çalışmalar incelendiğinde; Scott ve arkadaşları çalışmalarında, bir tel erozyon tezgahında kontrol parametrelerinin seçimi için çok amaçlı bir optimizasyon probleminin formülasyonunu ve çözümünü sunmuşlardır [1]. İlerleme hızının ve yüzey pürüzlülüğünün ana performans ölçümleri olarak alındığ bu çalışmada, performans ölçümlerinin değişik işleme koşullarında tahmini için bir faktöriyel tasarım modeli kullanılmıştır. Rajurkar ve Wang tel kopmasının fiziğini ısıl bir model yardımıyla analiz etmiştir. Çalışmada, optimum tezgâh ayarları için kesme hızı ve yüzey pürüzlülüğü arasındaki ilişki bir model yardımıyla belirlenmiştir [2]. Kozak ve arkadaşları PCD (polycrystalline diamond) plakaların işlenmiş yüzeyinin kalitesi ve kesme hızı üzerinde malzemenin tane boyutunun, boşalım enerjisinin ve deşarj frekansının etkisini sunmuşlardır [3]. Tarng vd. tel erozyon kesme performansının iyileştirilmesi amacıyla yaptıkları çalışmada, yapay sinir ağları kullanılarak kesme hızı ve yüzey pürüzlülüğünün belirlenmesi için puls süresi, puls ara süresi, işleme gerilimi, servo gerilim, boşalım akımı, boşalım kapasitansı ve tabla ilerleme hızının optimum değerlerini belirlemiştir [4]. Liao ve arkadaşları tel erozyondaki işleme parametrelerinin seçimi için yaptıkları optimizasyon çalışmasında Taguchi deney tasarım metodu ve varyans analizi kullanarak işleme performansına etki eden önemli faktörleri belirlemişlerdir [5]. Spedding ve Wang, yapay sinir ağları kullanarak yaptıkları modellemede tel erozyon işleme parametrelerinin optimizasyonunun yanında, tel erozyonda işlenmiş yüzeylerin tanımlamasını da yapmışlardır [6]. Lok ve Lee, iki seramik malzemeyi farklı kesme şartları altında işleyerek elde ettikleri farklı yüzey pürüzlülüğü ve kesme hızı değerlerini karşılaştırmışlardır [7]. Rozenek ve arkadaşları metal matrisli kompozit iş parçası kullandıkları çalışmalarında, puls süresi, puls ara süresi, boşalım akımı ve boşalım gerilimi gibi işleme parametrelerinin kesme hızı ve yüzey pürüzlülüğü üzerindeki etkisini incelemiş̧lerdir [8]. 
Tel erozyon ile işleme (WEDM) elektro erozyonla işlemenin (EDM) özel bir şeklidir. Burada elektrot, sürekli olarak ilerletilen iletken bir teldir. Tel erozyonda talaş, doğru akım vurumlu bir güç kaynağı vasıtasıyla oluşan elektrik kıvılcımlarının erozyonu ile kaldırılır. Kıvılcımlar dielektrik sıvı içerisinde birbirine yakın yerleştirilen tel elektrot ve iş parçası arasında oluşur. Tel erozyon ile işleme tekniğinin üstünlüğü, elektrik iletkenliği özelliğe sahip her türlü malzeme sertlik değeri ne olursa olsun işlenebilmekte, ayrıca kalın malzemelerin $(\sim 200 \mathrm{~mm})$ ve karmaşık profillerin işlenebilmesine imkân sağlamaktadır. Özellikle kalıp imalatında kullanımı yaygındır. Tezgâh ve kesime bağlı olarak tolerans $0.01 \mathrm{~mm}$ 'ye kadar inebilmektedir. Kesme boşluğu ise, tel çapı ve aşındırma bölgesi (akıma bağlı 1/2 tel çapı) kadardır. Bu nedenle dişi ve erkek kalıp yapımında büyük kolaylık sağlar [9].

Karışık şekle ve kesite sahip parçaları üretmek için geleneksel talaş kaldırma yöntemlerinden farklı olan tel erozyon tezgâhı ile işleme çok yaygın ve bilindik bir yöntemdir. Tel elektrot ve iş parçası arasındaki boşalımlar veya elektrik kıvılcımların rastgele dağıtılması sonucu dielektrik sıvı içerisine daldırılmış iletken malzemeden talaş kaldıran bir termal aşınma yöntemidir. Tel erozyonla işleme (WEDM), dünyada tornalama, frezeleme, taşlama ve diğer geleneksel işleme yöntemlerinin hepsinin yerini ald 1 [10].

Bilinen talaşlı imalat yöntemleri ile üretilen makine elemanlarının yüzey pürüzlülüğü değerlerini iyileştirmek için üretim maliyetlerini artıran bir dizi taşlama ve parlatma işlemleri yapılmaktadır. Tel erozyon ile üretilen makine parçaları ve kalıp elemanları ise bu işlem safhalarının bir ya da birkaçını atlayarak daha yüksek ölçü ve tolerans hassasiyetine sahip yüzey pürüzlülük değerleri neredeyse taşlama ile elde edilen yüzey pürüzlülük değerlerine yakın ürünler elde edilmektedir.

Teorik yüzey pürüzlülük değerleri $\mathrm{Rt}=\frac{f^{2}}{8 * r_{\varepsilon}} * 1000$ formülü esas alınarak talaşı imalatta kullanılan TNMG takım uçlarında 0.4-0.8 mm arasında uç yarıçapı değerleri, tel erezyon için tel kalınlıkları 0.05-0.35 mm tel çapları esas alınarak kıyaslanmaktadır.

$$
\begin{aligned}
f & =0.2 \\
r_{\text {tel }} & =0.125 \mathrm{~mm} \\
r_{u c ̧} & =0.4 \quad \mathrm{~mm} \quad \text { Olarak seçilmiştir. }
\end{aligned}
$$

TNMG uç 0.4 mm için teorik yüzey pürüzlülüğü;

$$
\begin{aligned}
\mathrm{Rt} & =\frac{f^{2}}{8 * r_{\varepsilon}} * 1000 \\
\mathrm{Rt} & =\frac{0.2^{2}}{8 * 0.4} * 1000 \\
\mathrm{Rt} & =12.5 \mu \mathrm{m}
\end{aligned}
$$

Tel erozyon tel çapı $0.25 \mathrm{~mm}$ için, mitutoyo SJ-201 yüzey pürüzlülük ölçüm cihazı ile yapılan ölçümlerde değerlerin 1,23-1,86 $\mu \mathrm{m}$ aralığında olduğu gözlemlenmiştir. Burada talaşlı imalat ve 
tel erozyonda imal temrinlerin ölçü tolerans değerleri, yüzey kalitesi, pürüzlülük değerlerini teorik ve deneysel olarak inceleyip, sonuçlarını kıyaslayarak makine ve imalat sanayinde üretim maliyetlerinin düşürülmesine yönelik bilimsel bir çalışma amaçlanmaktadır.

WEDM (tel erozyon tezgâhları) ile üretimin ve geleneksel imalat yöntemleri için gerekli maliyetlere hazırlanan tabloda değinilerek karşılaştırılmış ve sonuçlar üretim maliyetleri açısından incelenmiştir.

Farklı mühendislik çelikleri, üretimi zor ve karmaşık şekilli parçaların üretiminde sıkça başvurulan tel erozyon makinesi ile işleme metodu araştırmacılar tarafından defalarca deney hesaplamalarla kıyaslanarak denenmiştir.

Eliptik düz dişli çarklar, geleneksel imal yöntemleriyle üretilmesi oldukça zor olduğundan, CNC kumandasıyla donatılmış tel erozyon makinesinde işlenmiştir. Çalışma kapsamında, CNC tel erozyon makinesinde yer alan döndürme, kopyalama, ölçeklendirme ve makro programlama gibi APT fonksiyonları da kullanılmış ve eliptik düz dişli çarkın imalatı gerçekleştirilmiştir [11].

Çalışma kapsamında istenilen diş sayısı ve modülde eliptik düz dişli çarkların tasarımının AutoCAD ortamında kullanıcı etkileşimi olmaksızın elde edilmesi sağlanmış, üretimi istenilen her eliptik düz dişli çarkın imalatının gerçekleştirilebileceği ispat edilmiştir. Geleneksel olmayan yöntemlerden tel erozyon tezgâhı ile üretimin yapılabilir olması, metal ve plastik ekstrüzyon, plastik enjeksiyon yöntemiyle eliptik düz dişli çark üretiminin önü açılmıştır [11]. Araştırmacı tarafından yapılan çalışma neticesinde üretimi klasik imalat yöntemleri ile bir hayli zor olan eliptik dişli çark tel erozyon ile kesme yöntemi ile yüksek hassasiyet ve çalışma boşluğu ile imal edilebilmiştir.

Tel erozyonla kesme işlemi sonucunda, yüzeyde Beyaz Tabaka olarak isimlendirilen çok sert bir tabaka oluşmaktadır. Bu tabakanın yapısından dolayı, yüzey sertliği artmaktadır. Yüzeyden itibaren ana yapıya doğru sertlik azalması görülmektedir. Isıl işlemli D5 takım çeliklerinde diğer numunelerden farklı olarak yüzey altında aşırı temperlenmiş veya tavlanmış bir yapı görülmekte, bu da bu bölgedeki sertliğin ana matris sertliğinin altına kadar düşmesine neden olmaktadır. Alüminyum numunelerde, yüzey sertliği ve ısıdan etkilenen bölge genişliği 1sı iletiminin yüksek olmasından dolayı, nispeten daha düşük olmaktadır [12]. Araştırmacının iki farklı malzeme ile yaptığ inceleme neticesin de çelik dışı alaşımlarda da uygun puls süreleri ve kesme hızları ile üretimin sağlıklı olarak yapılabileceği gösterilmiştir.

Inconel 718, uzay ve havacılık endüstrisinde kullanılan şekillendirilmesi güç yüksek mukavemetli bir süper alaşım çeşidi olduğundan işlenme maliyetleri yüksektir. İşleme parametreleri, yapılan imalatın kalite ve ekonomikliğini doğrudan etkilediğinden seçimi çok iyi yapılmalıdır. Bu 
çalışmada, kalite ve ekonomikliğe tesir eden işleme süreleri, boyut hataları ve yüzey pürüzlülüğü gibi kriterlerin puls süresi, puls ara süresi ve SF faktörleri ile modellemeleri yapılarak birçok denklem elde edilmiştir. Bu denklemler ile yeni deneysel çalışmalara gerek duyulmadan istenilen boyutsal hatalara, işleme sürelerine ve yüzey pürüzlülük değerlerine ulaşılması mümkündür. $\mathrm{Bu}$ çalışma ile, Inconel 718 süper alaşımının kesme parametrelerinin; boyut, işleme süreleri ve yüzey pürüzlülük değerlerine olan etkileri literatüre kazandırılmıştır [13].

Tel erozyon tezgâhlarında, tel elektrotu gibi çok basit bir takım yardımı ile çok yüksek hızlarda bile üç boyutlu karmaşık parçaların büyük bir kısmı imal edilebilmektedir. Bu yöntem daha çok PCD (poli crystalline diamond), CBN (cubik boron nitride) ve silikon içerikli yüksek alaşımlı ve farklı iş parçalarının imalatında uygulanmaktadır. İş parçası ve tel malzemesi uygun seçilmesi halinde dakikada $300 \mathrm{~mm}^{2}$ ve hatta daha yüksek kesme değerlerine ulaşılabilmektedir [14].

T/M malzemelerin avantajları arasında sayılan talaşlı imalat gerektirmemesi veya en aza indirgenmesi işlene bilirliğinin araştırılmasına engel teşkil etmemektedir. Yüzey pürüzlülüklerinin iyileştirilmesinde veya mamul üzerinde bulunan elemanların (delikler, ince cidarlı kanatlar, vb.) işlenmesinde talaşlı üretime gereksinim duyulmaktadır. Bununla birlikte alaşım elementi içeren alüminyum (Al) esaslı T/M malzemelerin zayıf işlene bilirlikleri, yaygın olarak kullanımlarını engellemektedir. $\mathrm{Bu}$ tür $\mathrm{T} / \mathrm{M}$ malzemeler içerdikleri sert seramik parçacıklardan dolayı kesici takımların oldukça hızlı bir şekilde aşınmasına ve dolayısı ile yüksek takım maliyetine neden olurlar. Bundan dolayı, üretkenliği arttıracak ve işleme maliyetini minimum yapabilecek kesme şartlarını belirleyebilmek için en uygun işlene bilirlik parametrelerinin belirlenmesi gerekmektedir. Bu nokta da klasik işleme yöntemlerine göre (torna, freze, vb.) daha iyi yüzey pürüzlülük değerleri sunan ve malzeme iç yapısında da işlemeden kaynaklı iç gerilmelerin oluşumunda daha az etkili bir işleme tekniği olan tel elektro erozyon yöntemi akla gelmektedir [15].

\section{Metot}

Kalıp ve makine parçalarının imalat süreçlerinde istenilen ölçü tamlığı ve yüzey kalitesine ulaşmak için geleneksel imalat yöntemleri le üretilen malzemeler genellikle tesviye denilen ikincil üretim işlemlerine yahut yine geleneksel talaşlı imalat yöntemlerinden olan yüzey taşlama, silindirik taşlama vb. diğer yüzey işleme işlemlerine ihtiyaç duymaktadır.

$\mathrm{Bu}$ işlemler düzgün geometrik şekilli yahut karmaşık olmayan şekillerin işlenmesinde çok büyük sorunlar ortaya çıkarmazken, daha karmaşık yüzeyli profiller ve eğimli yüzeylerin işlenmesi konu olduğunda, işleme maliyetleri üzerine bir de bağlama aparatları ve fikstürlerin üretimi de dahil olmaktadır. Bu nedenle var olan imal maliyetlerine artı olarak ikincil yahut dolaylı üretim maliyetleri de eklenmektedir. Tel erozyon yahut EDM ile yapılan işlemlerde bu durum ortadan kaldırılarak bu maliyetler en düşük seviyeye indirilmektedir.

Aşağıda verilen tabloda Toloox 44 yeni nesil mühendislik çeliğinin işlendiği ön koşulu kabul edilmiş bir kalıp elemanı ya da makine parçasının 1 saatte üretildiği var sayılarak, araştırmamızda 
oluşturulan maliyet tablosu bulunmaktadır.

Tablo 1. Maliyet Gider Kalemleri Fiyat Listesi

\begin{tabular}{|l|c|c|}
\hline $\begin{array}{l}\text { Giydirilmiş Tasarımcı ve } \\
\text { Cam Operatörü Ücreti }\end{array}$ & 20 & Saat/TL \\
\hline $\begin{array}{l}\text { Giydirilmiş Makine } \\
\text { Operatörü Ureti }\end{array}$ & 16 & Saat/TL \\
\hline Giydirilmiş Tesviyeci Ücreti & 14 & Saat/TL \\
\hline $\begin{array}{l}\text { CNC Tezgâh günlük ücreti } \\
\text { Ostim /ANKARA bazında }\end{array}$ & 300 & Saat/TL \\
\hline $\begin{array}{l}\text { CNC WEDM ve EDM günlük } \\
\text { ücreti Ostim /ANKARA } \\
\text { bazında }\end{array}$ & 250 & Gün/TL \\
\hline $\begin{array}{l}\text { Toloox 44 Malzeme fiyatı } \\
\text { 33 x 20.3 x 500 mm için }\end{array}$ & 63 & Belirtilen ölçüde malzeme \\
için adet fiyatı. [3]
\end{tabular}

Yukarıda Tablo 1'de verilen saatlik ve adet bazında birim fiyatları aşağıda Tablo 2'de gösterilen piyasadan(Ankara Ostim Sanayi) topladığımız araştırmamızın verilerine göre tel erozyon kesim ve talaşlı imalat yöntemleri ile üretim karşılaştırılmıştır. 
Tablo 2. Maliyet Karşılaştırma Tablosu

\begin{tabular}{|c|c|c|c|c|}
\hline $\begin{array}{l}\text { Ana Maliyet } \\
\text { Kalemleri }\end{array}$ & $\begin{array}{l}\text { Tel Erozyon Tezgâhı } \\
\text { İşlenen } \\
\text { Parçalar için Maliyet } \\
\text { Kalemleri }\end{array}$ & $\begin{array}{c}\text { Birim Fiyat } \\
\text { (Saat/ücret) } \\
\text { ve } \\
\text { (adet/fiyat) }\end{array}$ & $\begin{array}{c}\text { Geleneksel Talaşlı } \\
\text { İmalat } \\
\text { Tezgâhları ile Yapılan } \\
\text { Üretim Maliyetler } \\
\text { Kalemleri }\end{array}$ & $\begin{array}{l}\text { Birim Fiyat } \\
\text { (Saat/ücret) } \\
\text { ve } \\
\text { (adet/fiyat) } \\
\end{array}$ \\
\hline \multirow{4}{*}{ İşçi ve İşçilik Maliyetleri } & $\begin{array}{l}\text { Tasarımcı ve CAM } \\
\text { operatörü } \\
\text { (Saat/ücret) }\end{array}$ & 20 & $\begin{array}{l}\text { Tasarımcı ve CAM } \\
\text { operatörü } \\
\text { (Saat/ücret) }\end{array}$ & 20 \\
\hline & Operatör (Saat/ücret) & 16 & $\begin{array}{l}\text { CNC Tezgâh Operatörü } \\
\text { (Saat/ücret) }\end{array}$ & 16 \\
\hline & Tesviyeci (Saat/ücret) & 14 & Tesviyeci (Saat/ücret) & 14 \\
\hline & & & $\begin{array}{l}\text { EDM makine Operatörü } \\
\text { (Saat/ücret) }\end{array}$ & 16 \\
\hline \multirow{2}{*}{ Makine Maliyetleri } & $\begin{array}{l}\text { Tel Erozyon Tezgâhı } \\
\text { (Saat/ücret) }\end{array}$ & 31,25 & $\begin{array}{l}\text { CNC tezgâh } \\
\text { (Saat/ücret) }\end{array}$ & 37,5 \\
\hline & & & $\begin{array}{l}\text { EDM tezgâh } \\
\text { (Saat/ücret) }\end{array}$ & 31,25 \\
\hline \multirow{3}{*}{ Malzeme Maliyeti } & Malzeme ücreti & 390,6 & Malzeme ücreti & 390,6 \\
\hline & Fire malzeme ücreti & - & Fire malzeme ücreti & 58,59 \\
\hline & & & Fire talaş ücreti & \\
\hline \multirow{3}{*}{ Kesici Takım Maliyeti } & $0,25 \mathrm{~mm}$ pirinç tel & 44,811 & Kaba talaş uç & 173,84 \\
\hline & & & Parmak freze & 496 \\
\hline & & & $\begin{array}{l}\text { Çapak alma } \\
\text { temizleme aparatı }\end{array}$ & 90 \\
\hline İkincil Üretim Maliyetleri & & - & $\begin{array}{l}\text { Keskin köşe ve radüsler } \\
\text { için } \\
\text { EDM elektrot tasarımı } \\
\text { ve üretimi }\end{array}$ & 0 \\
\hline Toplam Maliyet & & 516,661 & & 1343,78 \\
\hline
\end{tabular}

İşlenen yüzeylerin kalitesi, işlem performansı üzerinde önemli rol oynar. Kaliteli işlenmiş bir yüzey, yorulma mukavemetini, korozyon direncini ve sürtünme ömrünü önemli derecede iyileştirir. Yüzey pürüzlülüğü ayrıca yüzey sürtünmesine sebep olan temas, aşınma, 1sı iletimi, yağ filminin tutulması ve dağıtılması kabiliyeti, kaplama veya direnç ömrü gibi parçaların çeşitli fonksiyonel özelliklerini de etkiler. Bu sebeple istenilen yüzey tamlığı genellikle ön şart olarak belirlenir ve 
ihtiyaç duyulan kaliteye ulaşmak için uygun işlemler seçilir.

Talaşl1 imalatta yüzey pürüzlülüğünü etkileyen faktörleri şöyle sıralayabiliriz;

- Takım tezgâhının rijitlik durumu,

- Yataklama sisteminden kaynaklanan hatalar,

- Takım tutucu rijitlik durumu,

- Takım aşınmasının etkileri,

- Takım geometrisi,

- Kesme parametreleri,

- Malzemenin mekanik özellikleri,

- Soğutma sivisının etkileri.

- Bağlama kalıpları ve fikstür özellikleri,

\section{Sonuç ve Tartışma}

Temel olarak elektro boşalımlarla kesme işlemi (WEDM), esas itibari ile elektro-termal bir yöntemdir. Genellikle iş parçasının yüzeyi başka bir işleme tabi tutulmaz ve son yüzey olarak kabul edilir. WEDM'nin en önemli avantajlarından biri iş parçası ile tel elektrotu arasında hiçbir fiziksel (temasin) olmamasidır [16].

Belirtmek gerekir ki yüksek işleme hassasiyeti ve yüzey pürüzlülük değerlerini sağlayabilen tel erozyon ile imalat işlemleri birçok ikincil üretim ve takım maliyetlerini büyük oranda azaltmaktadır [17-18]. Talaş kaldırarak bir işlem gerçekleştirmediği için atık malzeme bir bütün olarak gerekli olabilecek ikincil üretim faaliyetine katılabilir yahut geri dönüşüm ayrıştırma, ayırma ve stoklanmasında kolaylık sağlayacaktır.

\section{Kaynaklar}

[1] Scott D., Boyina S., Rajurkar K. P., International Journal of Production Research, Analysis and optimization of parameter combinations in wire electrical discharge machining, 1991; Vol. 29, pp. 2189-2207,

[2] Rajurkar, K.P., Wang, W. M., Journal of Materials Processing Tech., Thermal modeling and on-line monitoring of wire-EDM, 1993; Vol. 38, 1-2, pp. 417-430.

[3] Kozak, J., Rajurkar, K.P., Wang, Z., J. Eng. Ind., Material Removal in WEDM of PCD Blanks, 1994; Vol. 116, 3, pp. 363-369.

[4] Tarng, Y.S., Ma, S.C. and Chung, L.K. INT. J. MACH. TOOL. MANU. Determination of optimal cutting parameters in wire electrical discharge machining. 1995; Vol. 35, pp.1693-170. [5] Liao, Y. S., Huang, J.T., Su, H.C., Journal of Materials Processing Technology, A study on the machining-parameters optimization of wire electrical discharge machining. 1997; Vol. .71, pp. 487-493. 
[6] Spedding, T.A., Wang, Z.Q., Precis Eng. Parametric optimization and surface characteristics of wire electrical discharge machining process. 1997; Vol.20-1, pp. 5- 15.

[7] Lok, Y.K., Lee, T.C., Processing of advanced ceramics using wire- cut EDM process. J. Mater Process Technol. 1997; Vol. 63, 1-3, pp.839- 843.

[8] Rozenek, M., Kozak, J., DabroVwki, L. and LubkoVwki, K., J. Mater. Process. Technol., Electrical discharge machining characteristics of metal matrix.composites. 2001; Vol. 109, pp.367370.

[9] Tosun N., Çoğun C., Mühendis ve Makine Dergisi, Tel Erozyonda Kesme Parametrelerinin İlerleme Hizına Etkisi , 2002; Cilt 43, Say1 515, pp.16-20.

[10] Ay M., Aydoğdu D, Makine Teknolojileri Elektronik Dergisi Tel Erozyonda Kesme Parametrelerinin Parçanın Boyut Ölçüsüne Etkilerinin Deneysel İncelenmesi, 2010; Vol. 7, pp. 3144.

[11] https://shop.premium-steel.eu/en_eu/tool-steel-ii/toolox-44/co-praz-flat-500-mm.html., 28/09/2019.

[12] Çaydaş U, Furat Üniversitesi Fen Bilimleri Enstitüsü, WEDM Yönteminde İşlem Parametrelerinin Mikroyapı ve Yüzey Pürüzlülüğüne Etkisi, Yüksek Lisans tezi, Elazığ, 2002.

[13] https://www.tezmaksanonline.com/parafinsiz-pirinc-tel/parafinsiz-pirinc-tel-1, 28/09/2019.

[14] Yazar M, Özdemir A, Politeknik Dergisi, Eliptik Düz Dişlilerin Bilgisayar Destekli Tasarımı ve CNC Tel Erozyon ile İmalatı, 2010; Cilt 13, Sayı 4, pp.245-253.

[15] Çaydaş U, Hasçalık A, DPÜ Fen Bilimleri Enstitüsü Dergisi, Cnc Tel Erozyon Tezgahlarında Farklı Malzemelerin İşlenebilirliğinin Araştırılması, 2004; Sayı, 6, pp.37-42.

[16] Doğan M., Marmara Üniversitesi Fen Bilimleri Enstitüsü, Inconel 718 MalzemesininTel Erozyon Tezgahında İşlenmesinde Kesme Parametrelerinin Kesme Performansına Etkisinin Deneysel Analizi Ve Optimum Parametrelerinin Tayini Yüksek Lisans Tezi, İstanbul,2010.

[17] Özek C., Özel C., DEÜ Mühendislik Fakültesi Fen ve Mühendislik Dergisi, Tel Erozyon Tezgahında Ç8620 Dişli Çeliğinin Kesilme Davranışlarının Araştırılması, 2003; Cilt 5, Sayı 2, s.47-52.

[18] Yurtkuran E., Karabük Üniversitesi Fen Bilimleri Enstitüsü, T/M ile Üretilmiş Alüminyum Esaslı Malzemelerin Alaşım Elementleri Ve Takviye Elemanı İçermelerine Bağlı Tel Erezyonda İşlenebilirliklerinin Araştırılması Yüksek Lisans Tezi, Karabük, 2011. 